\title{
CARACTERIZAÇÃO DA CURVA DE MATURAÇÃO DE PÊSSEGOS 'AURORA-1', NA REGIÃO DE JABOTICABAL-SP'
}

\author{
LUIS CARLOS CUNHA JUNIOR², MARIA FERNANDA BERLINGIERI DURIGAN², \\ BEN-HUR MATTIUZ ${ }^{3}$, RAMILO NOGUEIRA MARTINS ${ }^{2}$, JOSÉ FERNANDO DURIGAN ${ }^{3}$
}

RESUMO - O objetivo deste trabalho foi caracterizar a curva de maturação de pêssegos 'Aurora-1' para a região de Jaboticabal-SP, através de avaliações físicas e químicas dos frutos. O experimento foi conduzido em pomar comercial, no município de Vista Alegre do Alto, onde foram marcados ramos de 15 plantas, com flores no estádio de "balão". Após 20 dias, iniciou-se a coleta dos frutos, com intervalos de 7 dias, até a sua maturação completa (111 dias). Através dos dados de altura e de diâmetro, verificou-se que os frutos da cultivar 'Aurora-1' seguiram o padrão de crescimento semelhante ao encontrado na literatura, que é de uma curva sigmoidal dupla, atingindo no final da maturação altura de $59,84 \pm 6,9 \mathrm{~mm}$ e diâmetro de $50,30 \pm 5,8 \mathrm{~mm}$. Em relação ao peso dos frutos no período de 90 a 111 dias, houve incremento de $41,08 \mathrm{~g}$ para $58,82 \mathrm{~g} \mathrm{(43 \% ).} \mathrm{O} \mathrm{teor} \mathrm{de} \mathrm{ácidos} \mathrm{orgânicos} \mathrm{e} \mathrm{a} \mathrm{firmeza} \mathrm{diminuíram} \mathrm{na} \mathrm{mesma} \mathrm{proporção} \mathrm{em} \mathrm{que}$ ocorreu o aumento no conteúdo de sólidos solúveis e carboidratos solúveis durante o período de desenvolvimento. A coloração interna do fruto evoluiu, passando de amarelo-esverdeada para amarelo- intensa. A cor de fundo nas duas primeiras amostragens apresentaram valores semelhantes à cor interna, evoluindo a partir desse ponto de amarelo-esverdeada para alaranjada. Já a cor de recobrimento teve uma diferença mais pronunciada, passando de amarelo-esverdeada para vermelho-intensa, característica da cultivar. Esses resultados sinalizaram que, aos 90 e 97 dias, os frutos atingiram sua maturação fisiológica e que, aos 104 e 111 dias, encontravamse sobremaduros.

Termos para indexação: Prunus persica, estádio de desenvolvimento, maturidade fisiológica.

\section{CHARACTERIZATION OF THE MATURATION CURVE IN ‘AURORA-1’ PEACHES IN THE REGION OF JABOTICABAL-SP}

\begin{abstract}
The aim of this work was to characterize the maturation stage of peaches 'Aurora-1' for the region of Jaboticabal, SP, Brazil. The experiment was conduced in a commercial orchard in Vista Alegre do Alto, where branches of 15 trees were marked with flowers in "balloon" stage. After 20 days, fruits were harvested, every 7 days (or once a week) until the complete maturation of the fruits (111 days). Through the data of height and diameter, it was checked that the fruits of cultivar Aurora-1 showed the standard growth of sigmoidal double curves reaching in the end of maturation $59.84 \pm 6.9 \mathrm{~mm}$ of height and $50.30 \pm 5.8 \mathrm{~mm}$ of diameter. There was a development in the total mass of fruit of $41.08 \mathrm{~g}$ to $58.82 \mathrm{~g} \mathrm{(43 \% )} \mathrm{in} \mathrm{the} \mathrm{period} \mathrm{of} 90$ to 111 days. The titratable acidity and the firmness were reduced in the same proportion from the soluble solids and the soluble sugars contents increased during the growth period. The intern color of fruit developed from yellow-greenish to intensive yellow. The base color in the two first samplings showed values similar as of the intern color, from yellow-greenish to orange. Yet, the covering color had a stronger difference changing from yellow-greenish to intensive red, which is proper of the cultivar. These results showed that among 90 and 97 days the fruit reached their physiologic maturation and among 104 and 111 days, they were overripe.
\end{abstract}

Index Terms: Prunus persica, growth stage, physiologic maturity.

A produção brasileira de pêssegos no ano de 2004 foi de 235.720 toneladas, onde o Estado de São Paulo é o $2^{\circ}$ maior produtor nacional. Graças aos trabalhos de melhoramento genético, visando à obtenção de cultivares de pêssegos menos exigentes em frio, esse Estado passou a contribuir com $21 \%$ da produção nacional (Agrianual, 2007).

A cultivar de pêssego 'Aurora-1', além de apresentar pequena exigência de frio para a superação da dormência (abaixo de 100 horas), tem frutos de destacada qualidade organoléptica. O peso dos frutos é de 90-110 g com formato oblongo. A coloração da epiderme é amarela (coloração de fundo) com recobrimento de coloração vermelha, cobrindo até $80 \%$ do fruto. A polpa é firme, amarelo-clara, e com o caroço aderente à polpa. Os teores de sólidos solúveis são em média de $14{ }^{\circ}$ Brix com baixa acidez (Pereira et al., 2002). Segundo esses autores, o pêssego 'Aurora-1' apresenta um ciclo de 83 a 92 dias, na região de Jaboticabal.

\footnotetext{
1 ( Trabalho 088-07). Recebido em:30-03-2007. Aceito para publicação em: 26-09-2007.

${ }^{2}$ Aluno do Curso de Pós-Graduação em Produção Vegetal da UNESP-FCAV.

${ }^{3}$ Professor do Departamento de Tecnologia da Universidade Estadual Paulista. UNESP-FCAV, Câmpus de Jaboticabal. Via de Acesso Prof. Paulo Donato Castellane, s/n. 14.884-900. Jaboticabal-SP, Brasil. E-mail: benhur@fcav.unesp.br
} 
O fruto do pessegueiro é o resultado da diferenciação e do crescimento das paredes do ovário quando fecundado, sendo seu desenvolvimento caracterizado por uma curva sigmoidal dupla,com três estádios distintos. Durante o estádio I do desenvolvimento, há um rápido crescimento, devido à divisão celular. Já no estádio II, verificam-se importantes mudanças fisiológicas e anatômicas do fruto, como: diminuição do ritmo de crescimento da polpa, com endurecimento do caroço e formação parcial ou total da semente. No estádio III, a polpa retoma seu crescimento, aumentando os volumes celulares e os espaços intercelulares (Crane, 1969; Válio, 1979; Felippe, 1979; King et al., 1987).

No estádio III,ocorre a maturação, onde acontecem as principais mudanças físicas e bioquímicas do fruto, como a, produção de etileno e outros voláteis; mudanças na cor, na taxa respiratória, na permeabilidade dos tecidos e na textura; e transformações químicas que atingem os açúcares, ácidos orgânicos, proteínas, fenólicos, pigmentos e pectinas, entre outras. Durante a fase de amadurecimento, os sabores e odores específicos, juntamente com aumento na doçura e diminuição da acidez, tornam-se mais acentuados. É também nesse período que ocorre o amaciamento do fruto em conjunto com mudanças na coloração (Medeiros \& Raseira .,1998).

Conforme Medeiros \& Raseira (1998), para o mercado local ou venda direta ao consumidor, os frutos devem ser colhidos maduros, com certa firmeza e resistindo bem ao manuseio e ao transporte, e com as condições organolépticas desejáveis pelo consumidor. Já os frutos que serão armazenados antes de serem comercializados, devem estar firmes e terem iniciado o processo de amadurecimento, para evitar distúrbios fisiológicos que possam interferir na qualidade final do produto, depreciando-o e aumentando as perdas pós-colheita.

$\mathrm{Na}$ prática, os produtores de pêssego baseiam-se no tamanho e nas mudanças de coloração para efetuar a colheita, sem correlação com parâmetros físicos e químicos do fruto, levando muitas vezes o produtor à imprecisão, quanto ao estádio de maturação ideal para a comercialização dos pêssegos. Segundo Chitarra \& Chitarra (2005), o estádio de maturação no qual o pêssego é colhido, será decisivo para a sua vida de prateleira, bem como em relação ao seu potencial de armazenamento.

Segundo Sistrunk (1985), algumas das mudanças ocorridas durante a maturação dos pêssegos podem ser avaliadas por métodos físicos e químicos, sendo utilizadas como parâmetros para monitorar o progresso da maturação. Esses parâmetros são chamados de índices de maturação. A avaliação conjunta de alguns desses índices, como a firmeza da polpa, a coloração, o pH, os teores de sólidos solúveis e de acidez titulável, servem para identificar o estádio de maturação de frutas, bem como acompanhar o processo de amadurecimento após a colheita.

Dessa forma, justifica-se a execução de pesquisas na área, a fim de obter informações quanto à curva de maturação dos frutos da cultivar 'Aurora-1' para determinar o momento ideal da colheita.
O experimento foi conduzido em propriedade particular, situada no município de Vista Alegre do Alto, distante cerca de $40 \mathrm{~km}$ ao oeste do município de Jaboticabal-SP.

Em julho de 2005, foram marcados, com fita colorida, cerca de 200 ramos de pessegueiros da cultivar 'Aurora-1', distribuídos em 15 plantas do pomar. Para maior segurança, e buscando maior uniformidade, foram marcados somente ramos que continham flores no estádio denominado "balão" (antecede de dois a três dias a antese), que corresponde ao período que antecede em cerca de 1 a 2 dias a abertura total da flor. Transcorridos 20 dias após a marcação dos ramos, iniciou-se a coleta periódica a 7 dias dos pêssegos para análise, que perdurou até a completa maturação. Trinta frutos eram colhidos, ao acaso, e imediatamente levados ao Laboratório de Tecnologia dos Produtos Agrícolas da FCAV/UNESP, Jaboticabal, onde foram realizadas análises físicas e químicas.

As medidas de altura e diâmetro dos frutos foram realizadas com auxílio de paquímetro marca Mebo, sendo expressas em mm. A firmeza da polpa foi feita usando-se penetrômetro marca Bishop FT 327 com ponteira de $0,8 \mathrm{~cm}$, e os resultados expressos em N. A massa fresca foi avaliada através de pesagem em balança eletrônica Marte, modelo AS 2000, com precisão de $0,02 \mathrm{~g}$. O teor de sólidos solúveis (SS) foi determinado com o auxílio de um refratômetro digital Atago Palette, PR-101, conforme metodologia da AOAC (1997). A acidez titulável (AT) foi determinada com base no método da AOAC (1997). Os teores de carboidratos solúveis (CS) foram obtidos de acordo com técnica descrita por Faleiros (1978), e a determinação conforme Dubois et al. (1956), com resultados expressos em equivalente de gramas de glicose por 100 gramas de polpa.

A evolução da coloração interna e externa (cor de fundo e cor de recobrimento) foi feita com reflectômetro MINOLTACR $200 \mathrm{~b}$, onde foram determinados os valores de Luminosidade, Ângulo de cor e Cromaticidade (Minolta Corp., 1994).

Os dados relativos às medidas de altura e diâmetro são apresentados na Figura 1, onde se tem que os frutos da cultivar 'Aurora-1' seguiram o padrão de crescimento representado graficamente por uma curva sigmoidal dupla, onde os três estádios de desenvolvimento do fruto foram facilmente distinguidos. Esse comportamento evidenciou duas fases de crescimento exponencial - estádios I e III - e uma de crescimento reduzido - estádio II - com diminuição do crescimento da polpa e enrijecimento (ou lignificação) do caroço (Chalmers \& Ende, 1975).

A variação mais notável no crescimento ocorreu no estádio III, quando os pêssegos aumentaram rapidamente de tamanho, num período calculado de 33 dias (78 a 111 dias após floração). No final do período de desenvolvimento, os frutos apresentavam

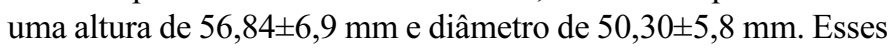
dados estão de acordo com BARBOSA et al. (1993) quando verificaram que pêssegos de maturação "ultraprecoce", "bem precoce" e "precoce" apresentaram um estádio III bem mais curto que as demais cultivares testadas, cerca de 22, 27 e 49 dias, respectivamente.

Os pessegueiros, dependendo de suas características de maturação, podem apresentar ciclos de desenvolvimento dos frutos com durações bastante diferenciadas, no Estado de São 
Paulo, variando de 80 a 200 dias (Lillien-Kipnis \& Lavee, 1971; Pereira et al., 2002). Mota e Nogueira-Couto (2002), estudando pessegueiros da cv 'Aurora-1', na região de Jaboticabal, relatam que o tempo de formação do fruto, desde o botão floral até a colheita, foi de aproximadamente 105 dias.

No estádio III, ocorrem as principais mudanças qualitativas no pêssego (Medeiros \& Raseira, 1998), o que corresponde ao período de 90 a 111 dias após a marcação das flores. Por isso foram realizadas análises destrutivas nesse período para relacionar com as não-destrutivas, principalmente a coloração a fim de auxiliar o produtor na determinação do ponto de colheita.

Pelos dados de coloração apresentados na Figura 2, observa-se que, no período de avaliação correspondente 90 a 111 dias, a luminosidade interna dos frutos permaneceu clara e constante durante o período de estudo. Entretanto, ocorreu evolução na cor, que passou de um amarelo-esverdeada para um amarelo intenso, indicado pela evolução dos valores de ângulo de cor $(111,54$ para 96,39$)$ e cromaticidade $(55,80$ para 60,50$)$. Quanto à coloração externa "cor de fundo", verifica-se que esta se tornou mais clara. Durante o período de 90 a 97 dias, verificouse que o ângulo de cor interna e a "cor de fundo" apresentaram valores muito próximos (Figura 2). A partir dessa data, verificouse que houve um decréscimo neste ângulo ("cor de fundo") que evoluiu de verde para amarelo (115,30 passando para 80,01), decorrente da degradação da clorofila por enzimas, como a clorofilase ou por modificações no $\mathrm{pH}$, e a síntese de carotenóides. Com relação à "cor de recobrimento", notaram-se diferenças ainda mais pronunciadas, pois à medida que o fruto se desenvolveu, ocorreu uma mudança significativa na cor, que passou de amareloesverdeada para vermelha, indicada pela drástica diminuição do ângulo de cor $\left(105,60^{\circ}\right.$ para $\left.26,60^{\circ}\right)$, o que denota uma elevada síntese de pigmentos carotenóides e antocianinas neste período.

Conforme classificação visual do estádio de maturação de pêssegos em "verdes", meio maduro" e "sobremaduro", preconizado por Medeiros e Raseira (1998), pode-se afirmar que os pêssegos 'Aurora 1', descritos no presente trabalho, encontraram-se nos respectivos estádios aos 83, 97 e 104 dias.
Na Figura 3, são mostradas as modificações físicas e químicas ocorridas em pêssegos 'Aurora-1', no período de 90 a 111 dias. Com relação à massa fresca, os frutos nas últimas três semanas aumentaram de peso de $41,08 \mathrm{~g}$ para $58,82 \mathrm{~g}$. Os valores aqui constatados estão abaixo dos $90-110 \mathrm{~g}$ citados por Pereira et al. (2002). Essa diferença pode ser explicada pela influência dos fatores climáticos predominantes no período de desenvolvimento das frutas, podendo resultar numa maturação diferenciada desses estádios.

Pode-se observar, na mesma figura, que há redução nos teores de acidez titulável na mesma proporção em que ocorre aumento no conteúdo de sólidos solúveis e açúcares solúveis. À medida que a fruta amadurece, parte dos sólidos é transformada em açúcares simples, como glicose, frutose e sacarose, gerando aumento nos teores de sólidos solúveis e açúcares solúveis (Chitarra \& Chitarra, 2005).

Na Figura 3, nota-se a redução da firmeza ao longo do período, ocorrido no estádio III. Com o amadurecimento do fruto, tem-se como característica o amaciamento da polpa, principalmente devido à absorção de água e à ação de enzimas, como pectinametilesterase e poligalacturonase, que atua nas pectinas. Essas duas enzimas são umas das principais se não as principais enzimas relacionadas com a queda de firmeza ocorrida nos frutos (Chitarra \& Chitarra, 2005; Kluge et al., 2002).

O principal parâmetro não-destrutivo para definir o estádio de maturação de uma fruta é a coloração. Entre os três parâmetros que a definem, o ângulo de cor tem maior destaque, por isso os pêssegos colhidos no estádio de maturação fisiológica "de vez" enquadram-se no período compreendido entre 90 e 97 dias após a marcação das flores com ângulo de cor variando entre 100-115 , e os frutos colhidos maduros correspondem ao período de 97 a 104 dias, com ângulo de cor compreendido entre $80-106^{\circ}$.

Para a região de Jaboticabal, a duração média dos estádios de maturação I, II e II, dos pêssegos da cv 'Aurora-1' foi de 21; 21 e 42 dias, respectivamente.

Os frutos apresentaram-se imaturos até os 90 dias, "de vez" entre 90 e 97 dias, maduros no período de 97 a 104 dias e "sobremaduros" a partir de 104 dias.

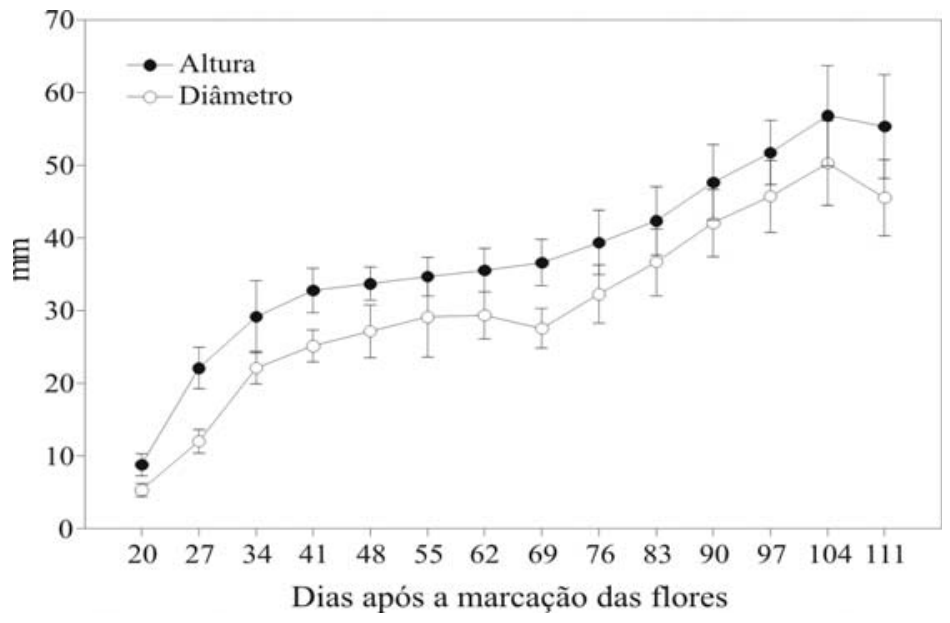

FIGURA 1 - Altura e diâmetro de pêssegos 'Aurora-1' durante seu desenvolvimento, em plantas cultivadas na região de JaboticabalSP, na safra $2005(n=30)$. 


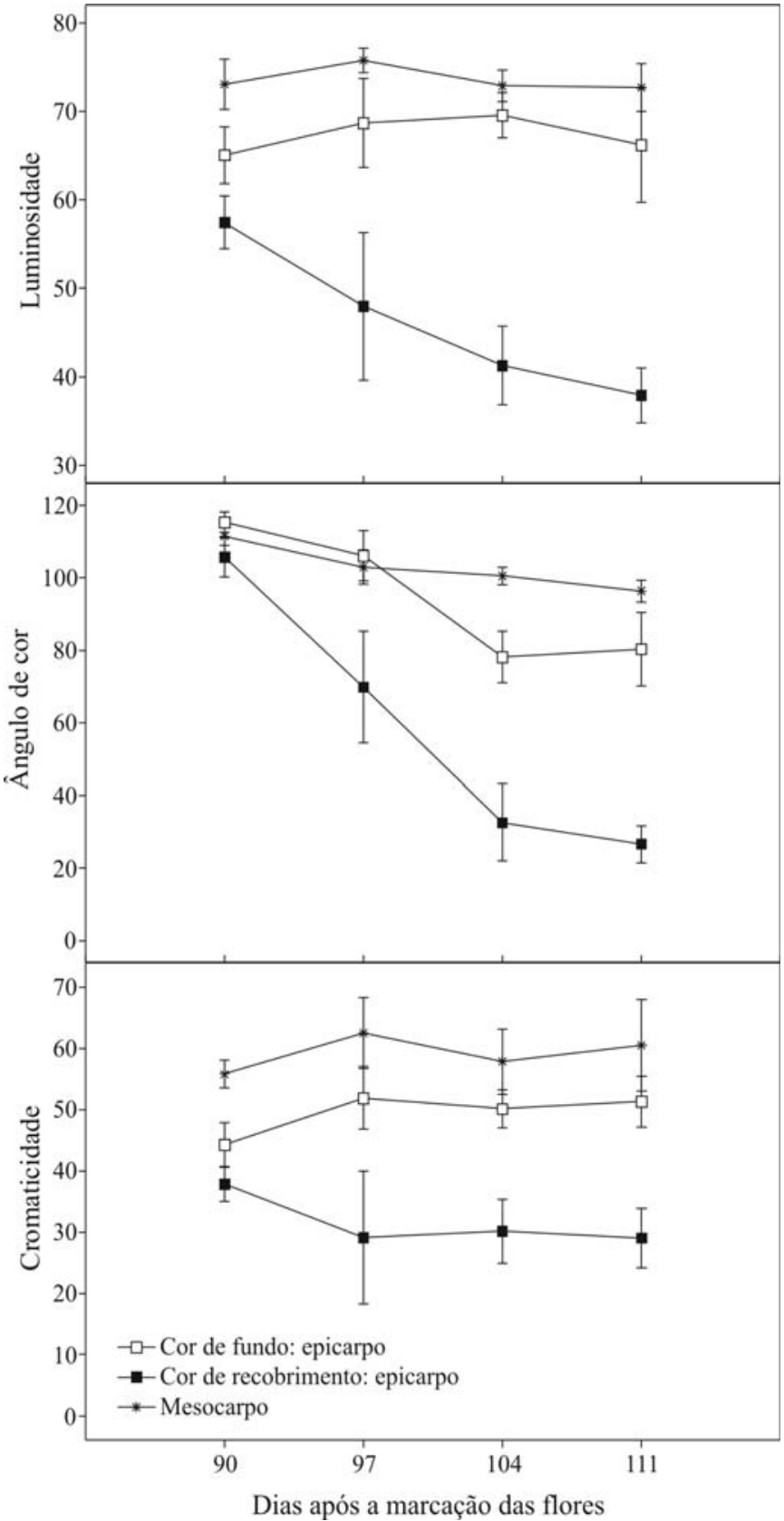

FIGURA 2- Coloração interna e externa de pêssegos 'Aurora-1' durante o estádio III de desenvolvimento, em planta cultivada na região de Jaboticabal -SP, na safra 2005. $(\mathrm{n}=10)$

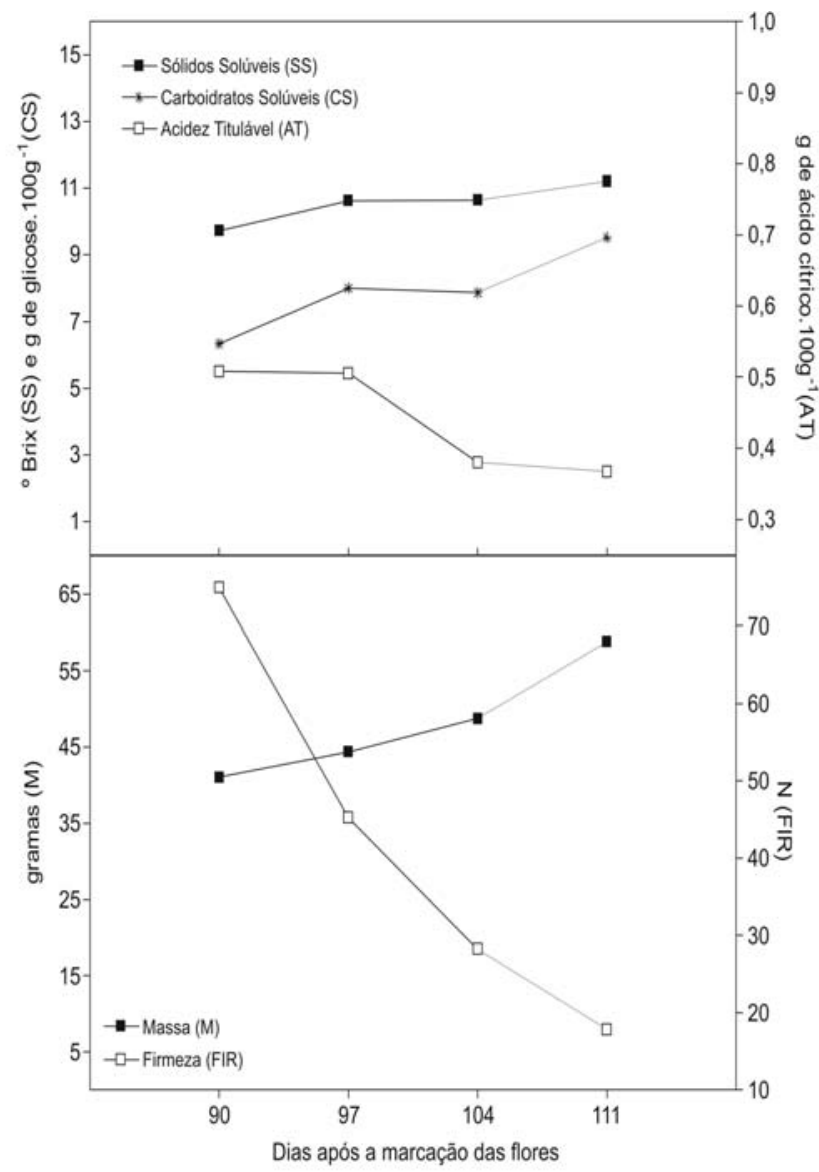

FIGURA 3- Avaliações físicas e químicas de pêssegos ‘Aurora1 ' durante o estádio III de desenvolvimento, em planta cultivada na região de Jaboticabal -SP, na safra $2005(n=6)$. 


\section{AGRADECIMENTOS}

Os autores agradecem à FAPESP (Proc. $n^{\circ} .04 / 12110-6$ ) e ao CNPq (Proc. $\mathrm{n}^{\circ}$. 473328/2004-6), pelo auxílio financeiro.

\section{REFERÊNCIAS}

AGRIANUAL. Anuário da Agricultura Brasileira-2007. 12 ed. São Paulo: FNP. 2007. p.436-442.

AOAC. Official methods of analysis of the Association of Analytical Chemists. 13 ${ }^{\text {th }}$ ed. Washington, 1997. 1018p.

BARBOSA, W.; OJIMA, M.; CAMPO-DALL'ORTO, F.A.C.; MARTINS, F.P.; LOVATE, A.A. Desenvolvimento dos frutos e das sementes de pêssegos subtropicais de diferentes ciclos de maturação. Pesquisa Agropecuária Brasileira, Brasília, v. 28, n. 6, p. 701-707, 1993.

CHALMERS, D.I.; ENDE, B. van den. A reappraisal of the growth and development of peach fruit. Australian Journal of Plant Physiology, Collingwood, v.2, p. 623-634, 1975.

CHITARRA, M.I.F.; CHITARRA, A.B. Pós-colheita de frutos e hortaliças: fisiologia e manuseio. Lavras: ESAL-FAEPE, 2005. 785 p.

CRANE, I.C. The role of hormones in fruit set and development. HortScience, Alexandria, v. 4, n. 2, p. 108-111, 1969

DUBOIS, M., GILLEWS, K.A, HAMILTON, J.K., REBER, P.A, SMITH, F. Colorimetric method for determination of sugar and related substances. Analytical Chemistry, Washington, v.8, n. 3, p. 350-6, 1956.

FALEIROS, R.R.S. Técnicas e experimentos de aulas práticas em bioquímica. Jaboticabal: Faculdade de Ciências Agrárias e Veterinárias, 1978. p.1-6 Apostila
FELIPPE, G.M. Etileno. In: FERRI, M.G. Fisiologia vegetal. São Paulo: EPU/EDUSP, 1979. v.2, p.163-192.

KING, G.A.; HENDERSON, K.G.; LILL, R.E. Growth and anatomical and ultrastructural studies of nectarine fruit wall development. Botanical Gazette, Chicago, v. 148, n. 3, p. 443-455, 1987.

KLUGE, R. A.; NACHTIGAL, J.C.; FACHINELO, J.C.; BILHAVA, A. B. Fisiologia e manuseio pós-colheita de frutas de clima temperado. Campinas: Livraria e Editora Rural, 2002.214 p.

KONICA MINOLTA. Precise color communication: color control from feeling to instrumentation. Japão, 1994. $49 \mathrm{p}$.

LILLIEN-KIPNIS, H.; LA VEE, S. Anatomical changes during the development of 'Ventura' peach fruits. Journal Horticultural Science, Ashford, v. 46, p. 103-110, 1971.

MEDEIROS, C.A.B.; RASEIRA, M.C.B. Acultura do pessegueiro. Brasília: Embrapa-SPI, 1998.350p

MOTA, M.O.S., NOGUEIRA-COUTO, R.H. Polinização entomófila em pêssego (Prunus persica L.). Brazilian Journal of Veterinary Research and Animal Science, São Paulo, v.39, n.3, p. 124-128, 2002.

PEREIRA, F.M.; NACHTIGAL, J.C.; ROBERTO, S.R. Tecnologia para a cultura do pessegueiro em regiões tropicais e subtropicais. Jaboticabal: FUNEP, 2002. 62 p.

SISTRUNK, W.A. Peach quality assessment: fresh and processed. In: PATTEE, H.E. (Ed.). Evaluation of quality of fruits and vegetables. Westport: AVI Publishing, 1985. p. 1-46.

VÁLIO. I.F.M. Frutificação. In: FERRI. M.G. Fisiologia vegetal. São Paulo: EPU/EDUSP, 1979. v. 2, p. 313-342. 